Nicolas Chrestian, MD

Nicolas Dupré, MD

Ziv Gan-Or, MD, PhD

Anna Szuto, MSc

Shiyi Chen, MSc

Anil Venkitachalam, MD

Jean-Denis Brisson, MD

Jodi Warman-Chardon,

MD

Sohnee Ahmed, MSc

Setareh Ashtiani, MSc

Heather MacDonald,

MSc

Noreen Mohsin, BSc

Karim Mourabit-Amari, MD

Pierre Provencher, MSc

Kym M. Boycott, MD,

$\mathrm{PhD}$

Dimitri J. Stavropoulos, $\mathrm{PhD}$

Patrick A. Dion, PhD

Peter N. Ray, PhD

Oksana Suchowersky, MD

Guy A. Rouleau, MD, $\mathrm{PhD}$

Grace Yoon, MD

Correspondence to Dr. Yoon: grace.yoon@utoronto.ca

Supplemental data at Neurology.org/ng

\section{Clinical and genetic study of hereditary spastic paraplegia in Canada OPEN}

\section{ABSTRACT}

Objective: To describe the clinical, genetic, and epidemiologic features of hereditary spastic paraplegia (HSP) in Canada and to determine which clinical, radiologic, and genetic factors determine functional outcomes for patients with HSP.

Methods: We conducted a multicenter observational study of patients who met clinical criteria for the diagnosis of HSP in the provinces of Alberta, Ontario, and Quebec from 2012 to 2015. Characteristics of the participants were analyzed using descriptive statistics. The main outcome measure for a subset of the cohort $(n=48)$ was the Spastic Paraplegia Rating Scale. We also used the SPATAX-EUROSPA disability stage (disability score) to assess disability $(n=65)$.

Results: A total of 526 patients were identified with HSP across the country, and 150 patients had a confirmed genetic diagnosis. Mutations were identified in 15 different genes; the most common were SPAST (SPG4, 48\%), ATL1 (SPG3A, 16\%), SPG11 (8\%), SPG7 (7\%), and KIAA0196 (SPG8, 5\%). The diagnosis of SPG4 was associated with older age at symptom onset $(p=0.0017)$. SPG 4 and SPG3A were less associated with learning disabilities compared to other subtypes of HSP, and SPG11 was strongly associated with progressive cognitive deficits (odds ratio $87.75,95 \%$ confidence interval 14.04-548.24, $p<0.0001$ ). SPG3A was associated with better functional outcomes compared to other HSP subtypes $(p=0.04)$ on multivariate analysis. The strongest predictor of significant disability was abnormal brain MRI $(p=0.014)$.

Conclusions: The most important predictors of disability in our HSP cohort were SPG11 mutations and abnormal brain MRI. Accurate molecular characterization of well-phenotyped cohorts and international collaboration are essential to establish the natural history of these rare neurodegenerative disorders. Neurol Genet 2017;3:e122; doi: 10.1212/NXG.0000000000000122

\section{GLOSSARY}

$\mathbf{A D}=$ autosomal dominant; $\mathbf{C l}$ = confidence interval; $\mathbf{H S P}=$ hereditary spastic paraplegia; $\mathbf{O R}=$ odds ratio; $\mathbf{S C A}=$ spinocerebellar ataxia; SE = standard error; SPRS = Spastic Paraplegia Rating Scale.

Hereditary spastic paraplegias (HSPs) are a very heterogeneous group of neurodegenerative disorders involving the corticospinal tracts. The estimated prevalence of HSP ranges from 0.5 to 5.3 per 100,000 people for autosomal dominant (AD) HSP and 0.0 to 5.3 per 100,000 for autosomal recessive (AR) HSP. ${ }^{1,2}$ From a clinical perspective, HSPs have traditionally been classified into 2 main groups: uncomplicated (or pure) and complicated (complex). Pure HSPs are characterized by slowly progressive lower extremity spasticity and weakness, corticospinal tract signs, variable hypertonic urinary disturbances, and mild reduction of lower extremity vibration

\footnotetext{
From the Division of Neurology (N.C., G.Y.), Division of Clinical and Metabolic Genetics (S. Ahmed, H.M., G.Y.), Department of Paediatrics, University of Toronto, The Hospital for Sick Children; Faculty of Medicine (N.C., N.D., J.-D.B., K.M.-A.), Laval University, Quebec City; Department of Neurological Sciences (N.D., P.P.), CHU de Québec; Department of Neurology and Neurosurgery (Z.G.-O., N.M., P.A.D., G.A.R.), McGill University, Montreal Neurological Institute, Quebec; Department of Medical Genetics (A.S.), University of Montreal, CHUM, Quebec; The Hospital for Sick Children Research Institute (S.C.), Child Health Evaluative Sciences/Biostatistics Design \& Analysis Unit, Toronto, Ontario; Department of Medicine (A.V., O.S.), Division of Neurology, Department of Medical Genetics (S. Ashtiani, O.S.), University of Alberta, Edmonton; Department of Genetics (J.W.-C., K.M.B.), Children's Hospital of Eastern Ontario, Ottawa; CHU de Québec (K.M.-A.), Hôpital Enfant-Jésus, Quebec City; Department of Paediatric Laboratory Medicine (D.J.S., P.N.R.), The Hospital for Sick Children, Toronto, Ontario; and Department of Molecular Genetics (P.N.R.), The University of Toronto, Canada.

Funding information and disclosures are provided at the end of the article. Go to Neurology.org/ng for full disclosure forms. The Article Processing charge was paid by the authors.

This is an open access article distributed under the terms of the Creative Commons Attribution-NonCommercial-NoDerivatives License 4.0 (CC BY-NC-ND), which permits downloading and sharing the work provided it is properly cited. The work cannot be changed in any way or used commercially without permission from the journal.
} 
sense and proprioception. Complex HSP forms are characterized by the presence of additional neurologic or nonneurologic features. ${ }^{3}$ Genotype-phenotype relationships are not straightforward as HSP symptoms may occur at any age from infancy through late adulthood, and the age at symptom onset, rate of symptom progression, and extent of disability are variable even within HSP families with the same mutation. HSPs are genetically heterogeneous, and at least 77 different loci and 60 genes have been shown to be associated with HSP. The protein products have diverse roles, which include intracellular trafficking, endoplasmic reticulum-associated degradation, nucleotide metabolism, myelination, and mitochondrial metabolism. ${ }^{4,5}$ Many forms of HSP have been reported in Canada, but the prevalence, clinical types, genetic characterization, and functional impact of this condition remain poorly studied. We present a cross-sectional study of the clinical and genetic characteristics and functional outcomes of a large cohort of Canadian patients with HSP.

METHODS Clinical assessment. Five hundred twenty-six patients with a clinical diagnosis of HSP were recruited from 6 major medical centers across Canada (Toronto, Quebec, Montreal, Edmonton, Calgary, and Ottawa) from February 1, 2012, to January 31, 2015. The diagnosis of HSP was based on previously published criteria. ${ }^{6}$ Blood samples and clinical data were collected after written consent was obtained from all study participants. Standardized clinical assessments were performed and included demographic information, family history, developmental history, and HSP core symptoms (age at onset, lower extremity weakness and spasticity, hyperreflexia, extensor plantar responses, and bladder dysfunction). Other clinical symptoms such as progressive cognitive deficits, ataxia, extrapyramidal movements, swallowing difficulties, and ocular motor abnormalities were also assessed. For a subset of patients $(\mathrm{n}=65)$, disability was evaluated using the SPATAX-EUROSPA disability score, ranging from 0 (no disability) to 7 (severe disability/confined to bed). We also used the Spastic Paraplegia Rating Scale (SPRS), a previously validated disease-specific outcome measure for a subset of patients $(n=48)$. The SPRS is a composite measure with the following subdomains: speed of gait, climbing stairs, quality of gait, arising from chair, quality of spasticity, weakness and contractures, and bladder dysfunction. All subdomains were rated on a scale between 0 and 4 with a maximum total score of $52.7,8$ Ancillary investigations such as brain MRI, electrophysiologic tests, and metabolic studies were also evaluated. Patients with cerebellar signs were screened for mutations in FXN, SACS, and the common spinocerebellar ataxias (SCAs 1-8) prior to being included in the study. The complete data collection form is available as appendix e-1 at Neurology.org/ng. All data were stored in a central database at McGill University.
Standard protocol approvals, registrations, and patient consents. This study was approved by the Research Ethics Boards of all institutions involved in the study (figure 1).

Genetic analysis/mutation screening. Genomic DNA was extracted from the peripheral blood according to standard procedures. ${ }^{9}$ For a subset of the cohort from the province of Ontario (37 patients), all exons and flanking intron sequences of a panel of 51 genes known to cause HSP were sequenced both in forward and reverse directions at the Hospital for Sick Children using nextgeneration sequencing techniques. Sanger validation was performed according to standard protocols using BigDye terminator v1.1 (Life Technologies, Carlsbad, CA), and sequencing products were separated on an Applied Biosystems model 3730 Capillary Sequencer (Life Technologies) and analyzed using SeqPilot software (JSI Medical Systems, Kippenheim, Germany). Wholeexome sequencing was performed on 108 samples from 51 families without a genetic diagnosis, using the Agilent SureSelect Human All Exon v4 kit for capture and targeted enrichment of the exome. The captured samples were sequenced in the Illumina HiSeq 2000/ 2500 system (Genome Québec Innovation Centre, Montreal, QC, Canada). The reads were then aligned against the human genome (GRCh37 assembly) using Burrows-Wheeler Aligner. ${ }^{10}$ Variant calling and annotation were performed using Genome Analysis ToolKit ${ }^{11}$ and Annotate Variation. ${ }^{12}$ The exome data were then screened for all known HSP-causing genes and mutations. ${ }^{13,14}$

Statistical analyses. For the purpose of statistical analysis, we analyzed only the 150 patients with a genetically confirmed diagnosis. Descriptive statistics were provided for demographic and clinical variables. Mean (SD), median, and interquartile range were calculated for continuous variables. Frequency count and percentages were provided for the categorical variables. We performed an ordered logistic regression to examine the association between ambulatory status and age at symptom onset. Linear regressions were used to analyze the association between disability and age at onset, and logistic regression was used to evaluate the association between disability and abnormal brain MRI. We investigated the association between genetic diagnoses and outcomes of interest including age at onset, disease duration, abnormal bladder function, swallowing difficulties, HSP-related symptoms, learning disabilities, speech delay, progressive cognitive deficits, motor delay, ambulatory status, age achieved walking, and disability scores. For each outcome of interest, we performed 5 univariate analyses with each gene as the covariate separately. Bonferroni correction technique was then used to adjust for multiple testing (adjusted $p$ value threshold is 0.01 ). Logistic regressions were performed for binary outcomes. In cases of data point separation issues, Firth's penalized likelihood approach was applied. Linear regressions were conducted for continuous outcomes. We conducted a multiple linear regression analysis to examine the association between disability score (assessed by the SPRS) and variables such as genes of interest, age at evaluation, disease duration, abnormal brain MRI, and ataxia.

RESULTS Genetic testing. Of the 526 patients who met the inclusion criteria, 150 (28.5\%) patients from 58 families were confirmed to have a genetic diagnosis. Mutations in a total of 15 different genes were identified in our cohort. The most frequent were SPAST (SPG4, 72 patients, 48\%), ATL1 (SPG3A, 24 patients, 16\%), SPG11 (12 patients, 8\%), SPG7 (10 patients, 7\%), and KIAA0196 (SPG8, 8 patients, 5\%). Mutations were also found in PLP1 (SPG2, 5 


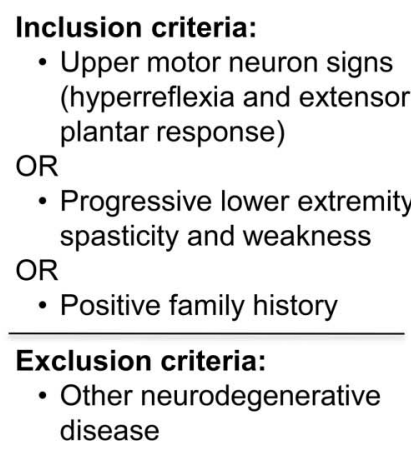

Patient referral by neurologist or geneticist to Canadian HSP center<smiles>C=[V]</smiles>

Recruitment centers:

Montreal, Quebec, Toronto, Ottawa, Edmonton, Calgary $(n=6)$

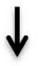

Met inclusion criteria

$(n=526)$

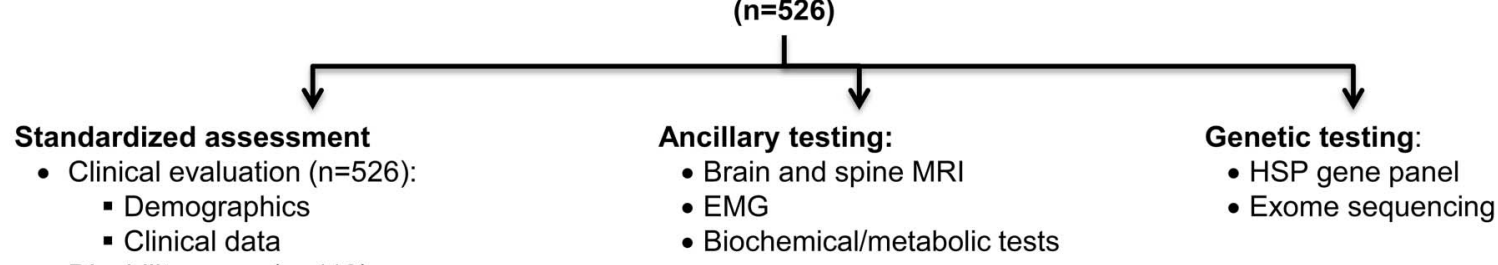

- Disability score $(n=113)$ :

- SPATAX-EUROSPA (65)

- Spastic Paraplegia Rating Scale (SPRS) (48)

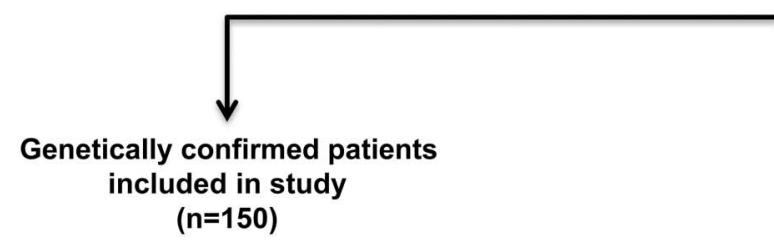

Patients with a clinical diagnosis of hereditary spastic paraplegia (HSP) were recruited from 6 major medical centers across Canada (Toronto, Quebec, Montreal, Edmonton, Calgary, and Ottawa) from February 1, 2012 , to January 31, 2015.

patients, 3\%), SLC2A1 (5 patients, 3\%), CYP7B1 1 patient, 0.6\%) (figure 2 and table e-1). A total of (SPG5A, 4 patients, 3\%), VAMP1 (3 patients, 2\%), 26 novel mutations were found in our cohort; they ALS2 (2 patients, 1\%), KIF5A (SPG10, 1 patient, were absent in publically available databases (Single 0.6\%), SLC16A2 (SPG22, 1 patient, 0.6\%), Nucleotide Polymorphism Database, 1000 Genomes ZFYVE26 (SPG15, 1 patient, 0.6\%), FA2H Project, and Exome Aggregation Consortium) and (SPG35, 1 patient, 0.6\%), and PNPLA6 (SPG39, were predicted to be pathogenic when evaluated using

Figure 2 Distribution of hereditary spastic paraplegia gene mutations in the study cohort

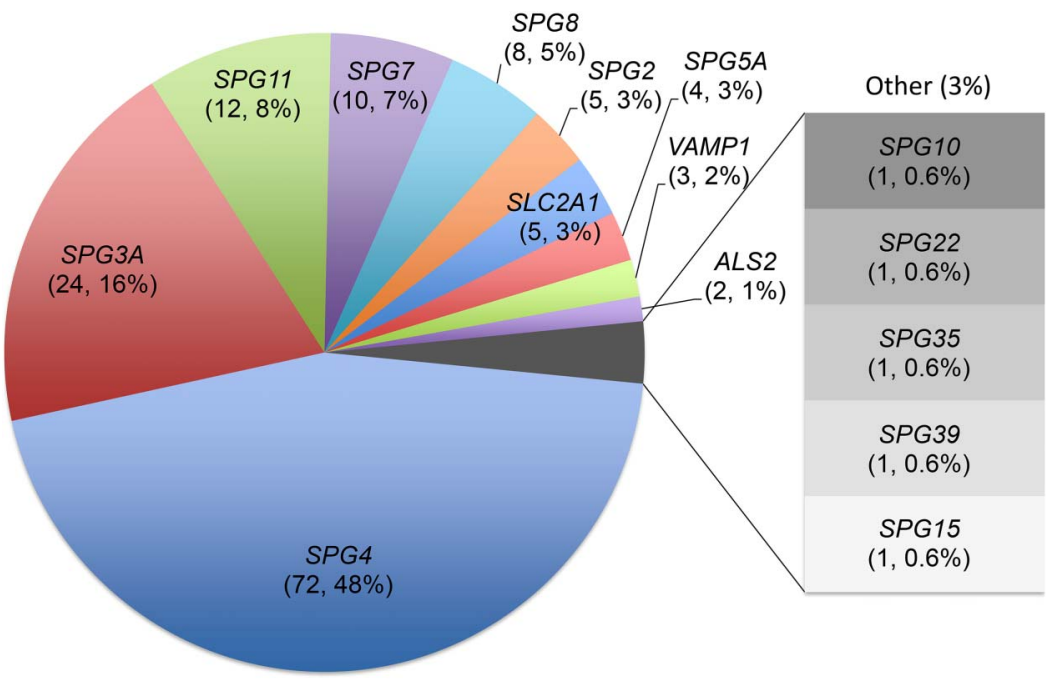

SPG4 and SPG3A were the most frequent autosomal dominant hereditary spastic paraplegia (HSP), while SPG11 followed by SPG7 were the most frequent autosomal recessive HSP. 
standard prediction programs (SIFT, PolyPhen, and Mutation Taster).

Clinical features. Seventy-eight of the 150 patients were men (52\%). Ethnic group was self-reported, and $65 \%$ of the cohort was from North America, $29 \%$ from Europe, 2\% from the Middle East, and $4 \%$ from Asia. Parental consanguinity was reported for $12 / 141$ patients (8.5\%). A positive family history (first-degree family members with symptoms of HSP) was reported by $87 \%$ of patients.

The mean age at evaluation of our cohort was 39.2 years (SD 22.1, range 1-82 years), and the mean age at onset of symptoms was 18.9 years (SD 18.6, range 0-67 years).

The majority of patients acquired independent walking by the age of 2 years (range less than 1 to 13 years). The most common clinical complaints, in addition to the core features of spasticity, weakness, and urinary disturbance, were dysarthria (33\%), sensory abnormalities (35\%), motor delay (24\%), peripheral neuropathy (23\%), speech delay (18\%), and ataxia (17\%). Less common symptoms included ocular motor disturbance (11\%), intentional tremor (11\%), and seizures (3\%).

Brain MRI was available for 60 patients. Brain imaging was abnormal in $28 \%$ of the cohort (17/ $60)$. The most common abnormalities reported were thin corpus callosum ( 6 patients, 10\%), followed by cerebellar atrophy (5 patients, $8 \%$ ), and white matter abnormalities (4 patients, 7\%). Two patients had nonspecific abnormalities on brain imaging.

Functional outcomes. At the time of evaluation for this study, 36/56 patients (64\%) required an aid for ambulation with the mean age at onset of mobility aid use of 33.6 years (SD 23.3, range 2-68 years). Twelve patients required the use of a cane $(21 \%)$ and 3 used a walker (5\%). Approximately one-third of our cohort was independent with respect to ambulation (20/56 patients, 36\%); however, 21 patients $(38 \%)$ were using a wheelchair. The mean SPRS for the subset of our cohort for which this was available (48 patients) was 19 (SD 11, range 2-39), and the majority of patients $(48 / 65,74 \%)$ had SPATAXEUROSPA disability scores within the mild to moderate range.

On univariate analysis, there was no statistically significant association between age at symptom onset and ambulatory status, nor was there a statistically significant association between age at symptom onset and SPRS score when adjusted for age at evaluation. There was a clear association between abnormal brain MRI and disability as measured by the SPRS, as patients with abnormal brain MRI had a mean higher SPRS score of 10.49 compared to those with normal brain imaging $(p=0.0037)$.
Genotype-phenotype correlations. Linear regression analysis with Bonferroni correction revealed that patients with SPG4 and SPG7 were more likely to develop symptoms later compared to other HSP subtypes, with a mean age at symptom onset of 24.6 (standard error $[\mathrm{SE}] 3.2)$ years for SPG4 ( $p=$ 0.0017 ) and 33 (SE 6.0) years for SPG7 $(p=$ 0.013). Patients with SPG3A were more likely to present at a younger age, with a mean age at symptom onset of 10.1 (SE 4.4) years $(p=0.022)$ (figure 3). SPG4 appeared to be associated with greater risk of bladder dysfunction (odds ratio (OR) 2.24, 95\% confidence interval (CI) 1.03-4.86, $p=0.04$ ), and patients with SPG3A less likely to develop bladder dysfunction (OR 0.30, 95\% CI 0.09-0.99, $p=$ $0.04)$, but these observations were not statistically significant following Bonferroni correction.

Similarly, SPG11 appeared to be associated with increased pain due to HSP-related symptoms compared to other genetic diagnoses (OR 5.44, 95\% CI $1.08-27.37, p=0.039$ ), but this was not statistically significant following Bonferroni correction. SPG2 appeared to be associated with an increased risk of speech delay (OR 18.33, 95\% CI 1.71-196.19, $p=0.016)$ and motor delay (OR 11.8, 95\% CI $1.14-122.1, p=0.04)$, and SPG4 less likely to have motor delay (OR 0.10, 95\% CI 0.01-0.78, $p=$ $0.028)$, but these observations were no longer statistically significant after Bonferroni correction. SPG11

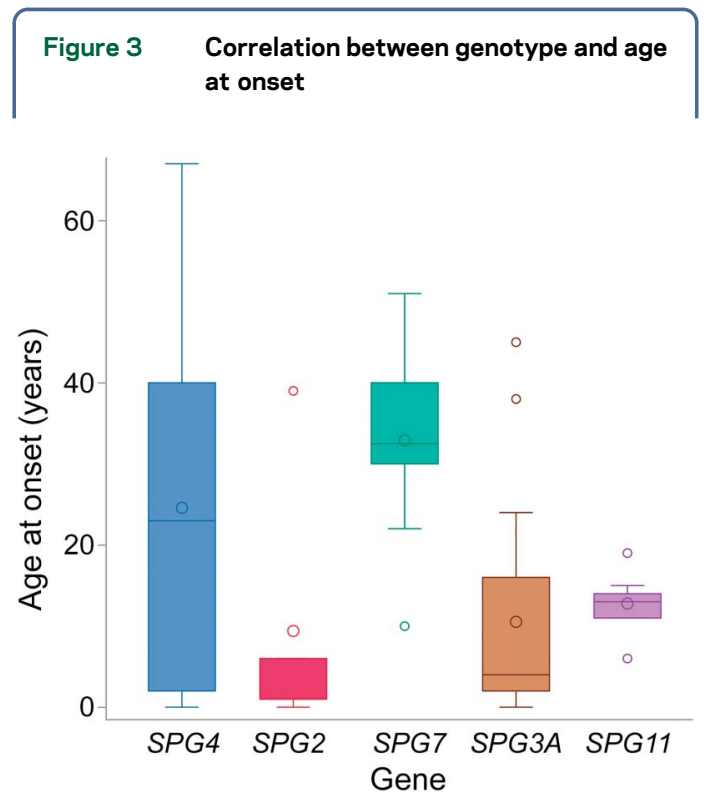

Patients with SPG4 and SPG7 were more likely to develop symptoms later compared to other hereditary spastic paraplegia subtypes, while patients with SPG3A were more likely to present at a younger age. The rectangles span the first quartile to the third quartile (interquartile range). The horizontal line inside the rectangle shows the median, and the "whiskers" above and below the box represent the minimum and maximum values of the ages at symptom onset. 
was strongly associated with an increased risk of learning disability (OR 30.59, 95\% CI 3.58-261.19, $p=$ 0.0018 ) and progressive cognitive deficits (OR 87.75, 95\% CI 14.04-548.24, $p<0.0001$ ), compared to other genetic subtypes of HSP. Patients with SPG4 were significantly less likely to have learning disability compared to those with mutations in other genes (OR 0.06, 95\% CI 0.01-0.51, $p=0.0096$ ). These remained statistically significant after Bonferroni correction.

Multiple linear regression analysis revealed that SPG3A patients had better functional outcomes with a mean lower SPRS score of 11.2 (SE 5.3) compared to those with mutations in other genes $(p=0.04)$, after adjusting for genotype, disease duration, and brain MRI status. Abnormal brain MRI was associated with a mean higher total SPRS score of 10.4 (SE $4.0)$ and worse functional outcomes compared with patients with normal brain MRI $(p=0.014)$.

DISCUSSION HSPs are clinically and genetically heterogeneous, and only a few population-based studies, mainly in relatively homogeneous populations, have been reported. ${ }^{2,15-19}$ We conducted a cross-sectional study of a large, ethnically diverse cohort of patients with HSP in Canada using standardized clinical assessments and specifically assessed functional outcomes using validated rating scales. As in previously published population-based studies, SPG4 and SPG3A were the most frequent AD-HSP. ${ }^{15,20,21}$ SPG4 accounts for up to $45 \%$ of AD-HSP and up to $20 \%$ of sporadic cases, ${ }^{22}$ while SPG3A accounts for nearly $10 \%$ of AD-HSP. ${ }^{18}$ SPG8 was present in $5 \%$ of our cohort, which is more common compared to previous reports. ${ }^{23}$ SPG11 followed by SPG7 were the most frequent AR-HSP, which is also in keeping with previously published studies. ${ }^{24,25}$

The primary analysis of the exome data was focused on known HSP genes; however, mutations were also found in genes not typically considered HSP genes in patients who met the clinical criteria for HSP (1 patient with a mutation in SLC16A2, 3 patients with mutations in $V A M P 1$, and 4 patients from a single family with mutations in SLC2A1). This has been observed by other groups and further highlights the clinical and genetic heterogeneity of HSP. ${ }^{19}$

In contrast to comparable neurodegenerative disorders such as the SCAs, very little is known about functional outcomes in patients with HSP, and the majority of studies are focused exclusively on SPG4 and SPG3A. ${ }^{20,26,27}$ This is likely due to very recent advances in genetic diagnoses of HSP compared to the common SCAs and highlights the need for good natural history data to identify parameters which influence clinical outcomes of HSP. ${ }^{28}$ There is one study which examined the correlation between disease duration and spasticity in patients with HSP, but unfortunately, the genetic diagnoses were not reported. ${ }^{29}$ Another study identified the degree of spasticity as being the most important contributing factor for wheelchair dependence. ${ }^{30}$ Higher SPRS scores have been shown to be inversely correlated with quality of life in a previous study. ${ }^{31}$ As the majority of patients in our cohort who met the clinical criteria for HSP did not have a genetic diagnosis, this illustrates the need for studies of clinical parameters which influence prognosis and outcomes for these patients. To our knowledge, only 1 recent study has focused on functional outcomes in a large genetically confirmed HSP population, the majority of which were adults with SPG4 of German ancestry. ${ }^{19}$ In contrast to the findings from this study, we did not observe a statistically significant association between disability scores and age at symptom onset or disease duration. This may reflect the underlying differences between our patient populations (ethnically diverse population from Canada vs primarily German ethnicity) and the large proportion of pediatric patients in our study. In our cohort, patients with SPG4 and SPG3A had less severe disability scores compared with other HSP genetic subtypes, and patients with SPG11 and SPG2 had more severe scores, although the samples sizes were too small for this observation to reach statistical significance. Bladder dysfunction is a recurrent and disabling symptom, ${ }^{32}$ which was present in a large proportion of our cohort, with the exception of patients with SPG3A, which may contribute to the better functional outcomes observed in this subgroup of patients.

The clear correlation between abnormal brain MRI and increased disability scores in our cohort confirms that brain imaging is an essential tool for clinical diagnosis and also for prognostication. ${ }^{33,34}$ The diagnostic utility of brain imaging to identify specific features of genetic subtypes of HSP such as SPG2, SPG7, SPG11, or SPG35 is well established. ${ }^{34,35}$ As an example, patients with SPG11 have thinning or agenesis (partial or complete) of the corpus callosum. ${ }^{36}$ They also demonstrate prominent cognitive impairment and learning disabilities, ${ }^{37,38}$ and some patients with SPG11 mutations present with a very rare phenotype (Kjellin syndrome) where mental retardation is a predominant feature. ${ }^{39}$ The clinical spectrum associated with SPG7 mutations is variable, but specific brain MRI findings such as cerebellar atrophy is common, which is consistent with ataxia being the first clinical symptom in many of these patients. ${ }^{40}$

Prospective studies of brain imaging in patients with HSP will be necessary to define the CNS phenotypes of the genetic HSP subtypes. The use of advanced 
techniques such as fractional anisotropy reduction, spinal morphometry, or diffusor tensor imaging brain will allow identification of imaging biomarkers which could be used to monitor the progression of the disease, and eventually used as outcome measures for future clinical trials.

One major strength of our study was the inclusion of both adult and pediatric patients, which enabled accurate assessment of age at symptom onset, and other clinical parameters essential for delineating the natural history of these disorders. Our study was limited by the relatively small sample sizes of the genetic subtypes of HSP, with the exception of SPG3A, SPG4, SPG11, and SPG7. The clinical variability between patients with the same genetic subtype, and even within the same family, renders accurate genotype-phenotype correlations difficult. Large prospective studies of well-phenotyped patients are required to define the natural history of the various HSP subtypes and to design appropriate clinical trials of therapies for these complex disorders.

CONCLUSION HSP is usually not a life-limiting disorder but can be associated with serious disability, and accurate genetic diagnosis, genetic counseling, and management of symptoms are essential to optimizing care for patients with HSP and their families. The Canadian HSP population is characterized by considerable clinical and genetic heterogeneity, yet we observed meaningful genotypephenotype correlations such as SPG4 and SPG7 presenting at later onset compared to SPG3A. SPG11 is strongly associated with abnormal brain MRI but also with prominent learning disabilities, progressive cognitive deficits, and poor functional outcomes. Patients with SPG3A and SPG4 have less disability and are less likely to develop cognitive deficits. Brain MRI is the most useful tool to predict functional outcomes and disabilities and should always be integrated in the clinical evaluation of any patient with suspected HSP.

Accurate molecular characterization of wellphenotyped cohorts and international collaboration to increase the power of future studies will be critical to establish the natural history of these rare degenerative disorders to enable future clinical trials.

\section{AUTHOR CONTRIBUTIONS}

Nicolas Chrestian contributed clinical data and wrote the first draft of the manuscript. Nicolas Dupré was responsible for the study concept and design; acquisition of data; analysis and interpretation; and critical revision of the manuscript for important intellectual content. Ziv Gan-Or performed the analysis of the whole-exome sequencing data and critically reviewed the manuscript for important intellectual content. Anna Szuto contributed clinical data and critically reviewed the manuscript for important intellectual content. Shiyi Chen performed the statistical analyses of the clinical data and critically reviewed the manuscript for important intellectual content. Anil Venkitachalam, Jean-Denis Brisson, Jodi Warman-Chardon, Sohnee Ahmed, Setareh Ashtiani, Heather MacDonald, and Noreen Mohsin contributed clinical data and critically reviewed the manuscript for important intellectual content. Karim MourabitAmari coordinated clinical molecular diagnostic testing; contributed clinical laboratory data; and critically reviewed the manuscript for important intellectual content. Pierre Provencher and Kym Boycott contributed clinical data and critically reviewed the manuscript for important intellectual content. Dimitri J Stavropoulos performed the clinical molecular testing; Sanger validation of variants and critically reviewed the manuscript for important intellectual content. Patrick A Dion performed the analysis of the whole-exome data and critically reviewed the manuscript for important intellectual content. Peter N. Ray performed the clinical molecular testing; Sanger validation of variants and critically reviewed the manuscript for important intellectual content. Oksana Suchowersky was responsible for the study concept and design; acquisition of data; and critical revision of the manuscript for important intellectual content. Guy A. Rouleau was responsible for the study concept and design; acquisition of data; analysis and interpretation; and critical revision of the manuscript for important intellectual content. Grace Yoon was responsible for the study concept and design; acquisition of data; analysis and interpretation; critical revision of the manuscript for important intellectual content; and overall study supervision.

\section{ACKNOWLEDGMENT}

The authors thank all the patients for participating in this study and the physicians who referred patients for the study. They also thank Winnie Lam, Sandra B. Laurent, Stephanie Strong, Dan Spiegelman, Alexandre Dionne-Laporte, Hélène Catoire, Daniel Rochefort, Megan Vanstone, and Pascale Hince for their excellent technical assistance.

\section{STUDY FUNDING}

This study was funded by CIHR Emerging Team Grant, in collaboration with the Canadian Organization for Rare Disorders (CORD), grant number RN127580-260005. The funding organization had no role in design and conduct of the study; collection, management, analysis, and interpretation of the data; and preparation, review, or approval of the manuscript. The corresponding author had full access to all the data in the study and takes responsibility for the integrity of the data and the accuracy of the data analysis.

\section{DISCLOSURE}

Dr. Chrestian reports no disclosures. Dr. Dupré has received travel funding/speaker honoraria from Actelion Pharmaceuticals and has served on the editorial board of Cerebellum \& Ataxia. Dr. Gan-Or has received travel funding and speaker honoraria from Sanofi-Genzyme and has received research support from the Canadian Institute of Health Research, McGill University, and the Michael J. Fox Foundation. Ms. Szuto, Ms. Chen, Dr. Venkitachalam, Dr. Brisson, and Dr. WarmanChardon report no disclosures. Ms. Ahmed is an employee of GeneDx. Ms. Ashtiani reports no disclosures. Ms. MacDonald has received research support from CIHR, in collaboration with the Canadian Organization for Rare Disorders (CORD). Ms. Mohsin, Dr. Mourabit-Amari, and Mr. Provencher report no disclosures. Dr. Boycott has served on the editorial boards of Human Molecular Genetics, Genetics, and Molecular Genetics and Genomic Medicine. Dr. Stavropoulos, Dr. Dion, and Dr. Ray report no disclosures. Dr. Suchowersky has received travel funding/ speaker honoraria from the American Academy of Neurology; has served on the editorial boards of the Canadian Journal of Neurological Sciences and Nature Reviews Neurology; has received publishing royalties from UpToDate for chapters on Diagnosis of Huntington Disease, Treatment of Huntington Disease, and Diagnosis of Chorea (and for yearly ongoing updates on these 3 chapters); has served on the advisory boards of Abbott (AbbVie) and Ipsen; has received research support from CIHR, NIH, CHDI, the Toupin Foundation, and AbbVie Pharmaceuticals; has acted as a consultant for AbbVie; and is supported by the Toupin Research Chair in Neurology, University of Alberta. Dr. Rouleau has received grants from CIHR, the ALS Association, Genome Québec, FRSQ, the ALS Society of Canada, and the Michael J. Fox Foundation. Dr. Yoon has received funding from CIHR and the Canadian Organization for Rare Disorders (CORD). Go to Neurology.org/ng for full disclosure forms.

Received June 30, 2016. Accepted in final form October 20, 2016. 


\section{REFERENCES}

1. Ruano L, Melo C, Silva MC, Coutinho P. The global epidemiology of hereditary ataxia and spastic paraplegia: a systematic review of prevalence studies. Neuroepidemiology 2014;42:174-183.

2. Erichsen AK, Koht J, Stray-Pedersen A, Abdelnoor M, Tallaksen CM. Prevalence of hereditary ataxia and spastic paraplegia in southeast Norway: a population-based study. Brain 2009;132:1577-1588.

3. Harding AE. Classification of the hereditary ataxias and paraplegias. Lancet 1983;1:1151-1155.

4. Blackstone C, O’Kane CJ, Reid E. Hereditary spastic paraplegias: membrane traffic and the motor pathway. Nat Rev Neurosci 2011;12:31-42.

5. Novarino G, Fenstermaker AG, Zaki MS, et al. Exome sequencing links corticospinal motor neuron disease to common neurodegenerative disorders. Science 2014;343: 506-511.

6. Gasser T, Finsterer J, Baets J, et al. EFNS guidelines on the molecular diagnosis of ataxias and spastic paraplegias. Eur J Neurol 2010;17:179-188.

7. Schule R, Holland-Letz T, Klimpe S, et al. The Spastic Paraplegia Rating Scale (SPRS): a reliable and valid measure of disease severity. Neurology 2006;67:430-434.

8. Adry RA, Lins CC, Kruschewsky Rde A, Castro Filho BG. Comparison between the spastic paraplegia rating scale, Kurtzke scale, and Osame scale in the tropical spastic paraparesis/myelopathy associated with HTLV. Rev Soc Bras Med Trop 2012;45:309-312.

9. Miller SA, Dykes DD, Polesky HF. A simple salting out procedure for extracting DNA from human nucleated cells. Nucleic Acids Res 1988;16:1215.

10. Li H, Durbin R. Fast and accurate short read alignment with Burrows-Wheeler transform. Bioinformatics 2009; 25:1754-1760.

11. McKenna A, Hanna M, Banks E, et al. The Genome Analysis Toolkit: a MapReduce framework for analyzing next-generation DNA sequencing data. Genome Res 2010;20:1297-1303.

12. Wang K, Li M, Hakonarson H. ANNOVAR: functional annotation of genetic variants from high-throughput sequencing data. Nucleic Acids Res 2010;38:e164.

13. Fink JK. Hereditary spastic paraplegia: clinico-pathologic features and emerging molecular mechanisms. Acta Neuropathologica 2013;126:307-328.

14. Finsterer J, Loscher W, Quasthoff S, Wanschitz J, AuerGrumbach M, Stevanin G. Hereditary spastic paraplegias with autosomal dominant, recessive, $\mathrm{X}$-linked, or maternal trait of inheritance. J Neurol Sci 2012;318:1-18.

15. Braschinsky M, Luus SM, Gross-Paju K, Haldre S. The prevalence of hereditary spastic paraplegia and the occurrence of SPG4 mutations in Estonia. Neuroepidemiology 2009;32:89-93.

16. McMonagle P, Webb S, Hutchinson M. The prevalence of "pure" autosomal dominant hereditary spastic paraparesis in the island of Ireland. J Neurol Neurosurg Psychiatry 2002; 72:43-46.

17. Lan MY, Chang YY, Yeh TH, et al. High frequency of SPG4 in Taiwanese families with autosomal dominant hereditary spastic paraplegia. BMC Neurol 2014;14:216.

18. Kwon MJ, Lee ST, Kim JW, Sung DH, Ki CS. Clinical and genetic analysis of a Korean family with hereditary spastic paraplegia type 3. Ann Clin Lab Sci 2010;40: 375-379.
19. Schule R, Wiethoff S, Martus P, et al. Hereditary spastic paraplegia -clinico-genetic lessons from 608 patients. Ann Neurol 2016;79:646-658.

20. Loureiro JL, Brandao E, Ruano L, et al. Autosomal dominant spastic paraplegias: a review of 89 families resulting from a portuguese survey. JAMA Neurol 2013;70:481-487.

21. Kim TH, Lee JH, Park YE, et al. Mutation analysis of SPAST, ATL1, and REEP1 in Korean patients with hereditary spastic paraplegia. J Clin Neurol 2014;10:257-261.

22. Magariello A, Muglia M, Patitucci A, et al. Mutation analysis of the SPG4 gene in Italian patients with pure and complicated forms of spastic paraplegia. J Neurol Sci 2010;288:96-100.

23. Schule R, Schols L. Genetics of hereditary spastic paraplegias. Semin Neurol 2011;31:484-493.

24. Erichsen AK, Stevanin G, Denora P, Brice A, Tallaksen CM. SPG11-the most common type of recessive spastic paraplegia in Norway? Acta Neurol Scand Suppl 2008; 188:46-50.

25. van Gassen KL, van der Heijden CD, de Bot ST, et al. Genotype-phenotype correlations in spastic paraplegia type 7: a study in a large Dutch cohort. Brain 2012;135:29943004 .

26. Chan E, Charles P, Ribai P, et al. Quantitative assessment of the evolution of cerebellar signs in spinocerebellar ataxias. Mov Disord 2011;26:534-538.

27. Tabrizi SJ, Scahill RI, Owen G, et al. Predictors of phenotypic progression and disease onset in premanifest and early-stage Huntington's disease in the TRACK-HD study: analysis of 36-month observational data. Lancet Neurol 2013;12:637-649.

28. Velazquez-Perez L, Rodriguez-Labrada R, Canales-Ochoa N, et al. Progression markers of Spinocerebellar ataxia 2. A twenty years neurophysiological follow up study. J Neurol Sci 2010;290:22-26.

29. Braschinsky M, Parts K, Maamagi H, Gross-Paju K, Haldre S. Functional assessment of lower extremities in hereditary spastic paraplegia. Arch Phys Med Rehabil 2009;90: 1887-1890.

30. Marsden J, Ramdharry G, Stevenson V, Thompson A. Muscle paresis and passive stiffness: key determinants in limiting function in Hereditary and Sporadic Spastic Paraparesis. Gait posture 2012;35:266-271.

31. Braschinsky M, Zopp I, Kals M, Haldre S, Gross-Paju K. Bladder dysfunction in hereditary spastic paraplegia: what to expect? J Neurol Neurosurg Psychiatry 2010; 81:263-266.

32. Klimpe S, Schule R, Kassubek J, et al. Disease severity affects quality of life of hereditary spastic paraplegia patients. Eur J Neurol 2012;19:168-171.

33. Franca MC Jr, Yasuda CL, Pereira FR, et al. White and grey matter abnormalities in patients with SPG11 mutations. J Neurol Neurosurg Psychiatry 2012;83:828-833.

34. Pensato V, Castellotti B, Gellera C, et al. Overlapping phenotypes in complex spastic paraplegias SPG11, SPG15, SPG35 and SPG48. Brain 2014;137:1907-1920.

35. Kubota K, Saito Y, Ohba C, et al. Brain magnetic resonance imaging findings and auditory brainstem response in a child with spastic paraplegia 2 due to a PLP1 splice site mutation. Brain Dev 2015;37:158-162.

36. Stromillo ML, Malandrini A, Dotti MT, et al. Structural and metabolic damage in brains of patients with SPG11related spastic paraplegia as detected by quantitative MRI. J Neurol 2011;258:2240-2247. 
37. Siri L, Battaglia FM, Tessa A, et al. Cognitive profile in spastic paraplegia with thin corpus callosum and mutations in SPG11. Neuropediatrics 2010;41:35-38.

38. Stevanin G, Azzedine H, Denora P, et al. Mutations in SPG11 are frequent in autosomal recessive spastic paraplegia with thin corpus callosum, cognitive decline and lower motor neuron degeneration. Brain 2008;131:772-784.
39. Puech B, Lacour A, Stevanin G, et al. Kjellin syndrome: long-term neuro-ophthalmologic follow-up and novel mutations in the SPG11 gene. Ophthalmology 2011;118: 564-573.

40. Elleuch N, Depienne C, Benomar A, et al. Mutation analysis of the paraplegin gene (SPG7) in patients with hereditary spastic paraplegia. Neurology 2006;66:654-659. 


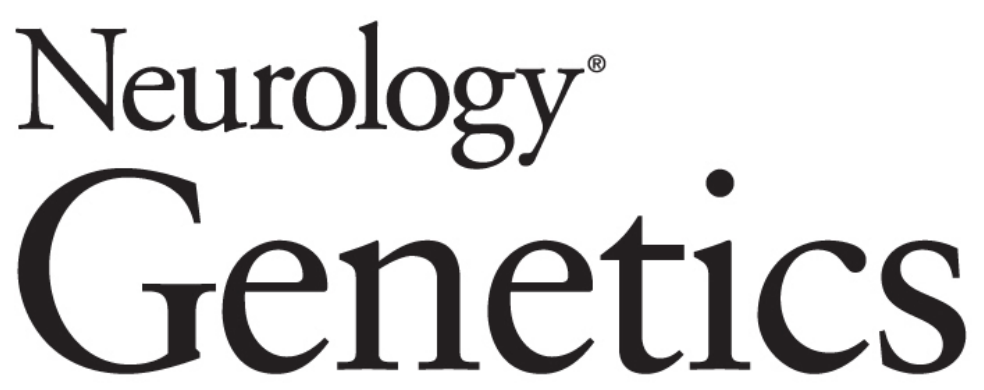

Clinical and genetic study of hereditary spastic paraplegia in Canada Nicolas Chrestian, Nicolas Dupré, Ziv Gan-Or, et al. Neurol Genet 2017;3;

DOI 10.1212/NXG.0000000000000122

This information is current as of December 5, 2016

Neurol Genet is an official journal of the American Academy of Neurology. Published since April 2015, it is an open-access, online-only, continuous publication journal. Copyright Copyright $@ 2016$ The Author(s). Published by Wolters Kluwer Health, Inc. on behalf of the American Academy of Neurology. All rights reserved. Online ISSN: 2376-7839.

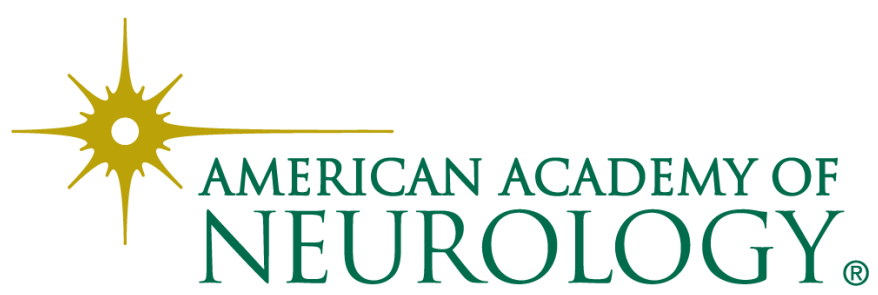




\section{Updated Information \& Services}

\section{Supplementary Material}

\section{References}

Citations

Subspecialty Collections

Permissions \& Licensing

\section{Reprints}

including high resolution figures, can be found at: http://ng.neurology.org/content/3/1/e122.full.html

Supplementary material can be found at: http://ng.neurology.org/content/suppl/2016/12/05/3.1.e122.DC1 http://ng.neurology.org/content/suppl/2017/03/06/3.1.e122.DC2

This article cites 40 articles, 6 of which you can access for free at: http://ng.neurology.org/content/3/1/e122.full.html\#\#ref-list-1

This article has been cited by 6 HighWire-hosted articles: http://ng.neurology.org/content/3/1/e122.full.html\#\#otherarticles

This article, along with others on similar topics, appears in the following collection(s):

All Genetics

http://ng.neurology.org//cgi/collection/all_genetics

Spastic paraplegia

http://ng.neurology.org//cgi/collection/spastic_paraplegia

Information about reproducing this article in parts (figures,tables) or in its entirety can be found online at:

http://ng.neurology.org/misc/about.xhtml\#permissions

Information about ordering reprints can be found online: http://ng.neurology.org/misc/addir.xhtml\#reprintsus

Neurol Genet is an official journal of the American Academy of Neurology. Published since April 2015, it is an open-access, online-only, continuous publication journal. Copyright Copyright $\odot 2016$ The Author(s). Published by Wolters Kluwer Health, Inc. on behalf of the American Academy of Neurology. All rights reserved. Online ISSN: 2376-7839.

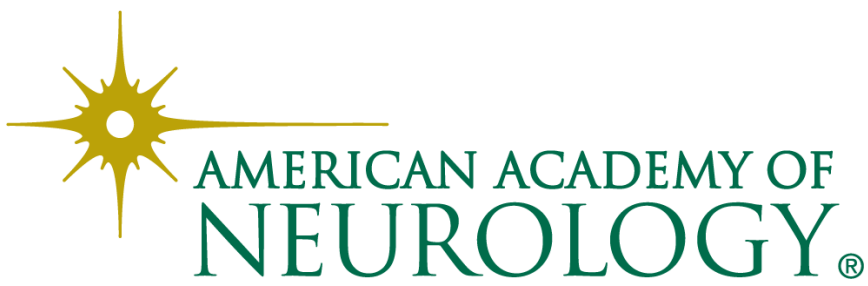

